\title{
Foreign body reaction to bone wax an unusual cause of persistent serous discharge from iliac crest graft donor site and the possible means to avoid such complication - a case report
} Abdul Qayum and Abid Hussain Koka*

\author{
Address: Department of Orthopaedics, SKIMS Medical College, Srinagar, India \\ Email: Abdul Qayum - sirfqayum@yahoo.co.in; Abid Hussain Koka* - abidkoka@yahoo.co.in \\ * Corresponding author
}

Published: 27 November 2009

Cases Journal 2009, 2:9097 doi:10.1 186/1757-1626-2-9097

This article is available from: http://www.casesjournal.com/content/2/1/9097

(c) 2009 Qayum and Koka; licensee BioMed Central Ltd.

This is an Open Access article distributed under the terms of the Creative Commons Attribution License (http://creativecommons.org/licenses/by/2.0), which permits unrestricted use, distribution, and reproduction in any medium, provided the original work is properly cited.
Received: 2 October 2009

Accepted: 27 November 2009

\begin{abstract}
Introduction: Bone wax is sometimes used in a variety of surgical procedures as a haemostatic. Bone wax contains beeswax softened with isopropyl palmitate or paraffin. It is nonabsorbable with no biochemical action. It achieves haemostasis by occluding the blood channels mechanically. Once applied it essentially never goes away. Bone wax reactions have been reported in literature many times.
\end{abstract}

Case presentation: We report a case in which bone wax was used to control bleeding at the iliac crest from which bone graft was harvested. The foreign body reaction to bone wax caused persistent discharge from iliac crest graft donor site.

Conclusion: Bone wax is a foreign body and that there is always a possibility of foreign body granulomas following its use. When necessary, bone wax should be used just for the time needed to achieve hemostasis. If it is left in place, care should be taken to avoid bone wax accumulation in the bony craters formed during surgery. Applying bone wax as a smooth layer may lead to this lumpy formation in the bony craters and one should be careful about it.

\section{Case presentation}

A 43 year old female patient of Indian origin came to our hospital with nonunion fracture shaft of right humerus. She was treated elsewhere with closed reduction and Uslab for her fracture initially. Her fracture showed no signs of union even after 8 weeks of conservative treatment. Open reduction and internal fixation with narrow dynamic compression plate with cancellous bone grafting was done. Graft was taken from iliac crest right side.

She was discharged from the hospital $4^{\text {th }}$ day post surgery after inspecting her wound sites which were healthy. Suture removal was done on $11^{\text {th }}$ day.
She reported to hospital again on $14^{\text {th }}$ day with serous discharge from the graft wound. Her wound was alright with serous discharge coming out of a $3 \mathrm{~mm}$ hole in the wound. The edges were not indurated or red. Her ESR, CRP and blood counts were within normal limits. Culture of the discharge persistently was sterile. She was continued with dressings but the serous discharge was persistent and copious. Surgical exploration of the graft donor site was done. A thin layer of tissue was found at the graft donor site which was curetted out. Bone wax pieces were found in the craters at the iliac crest (Fig 1 \&2) which was used at the time of bone grafting to control bleeding. The material was sent for histopathological examination 


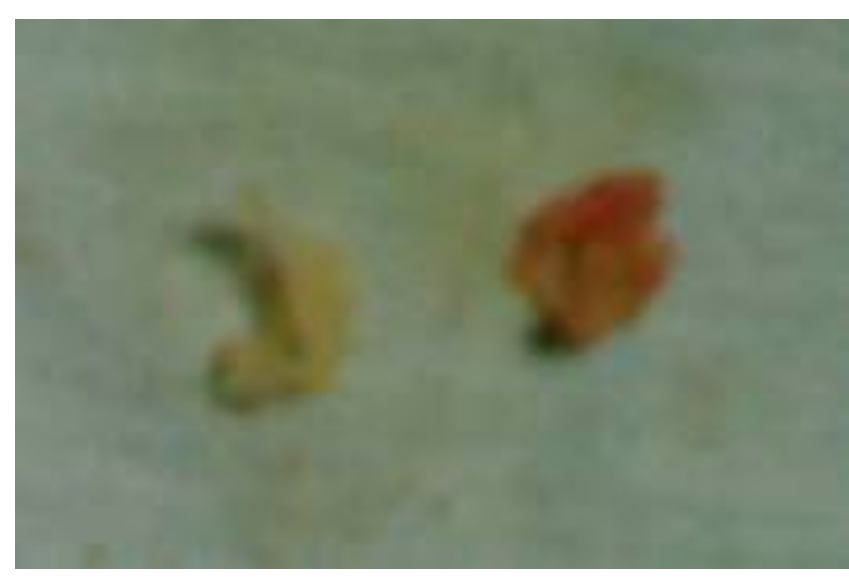

Figure I

Pieces of bone wax curetted out from the bony craters.

which confirmed it as wax material. The wound of the patient healed normally with no discharge in future. Her fracture of humerus united well.

\section{Discussion}

Bone wax was developed by Horsley in 1886 [1]. It contains beeswax softened with isopropyl palmitate or paraffin. It is used in many surgical procedures to control

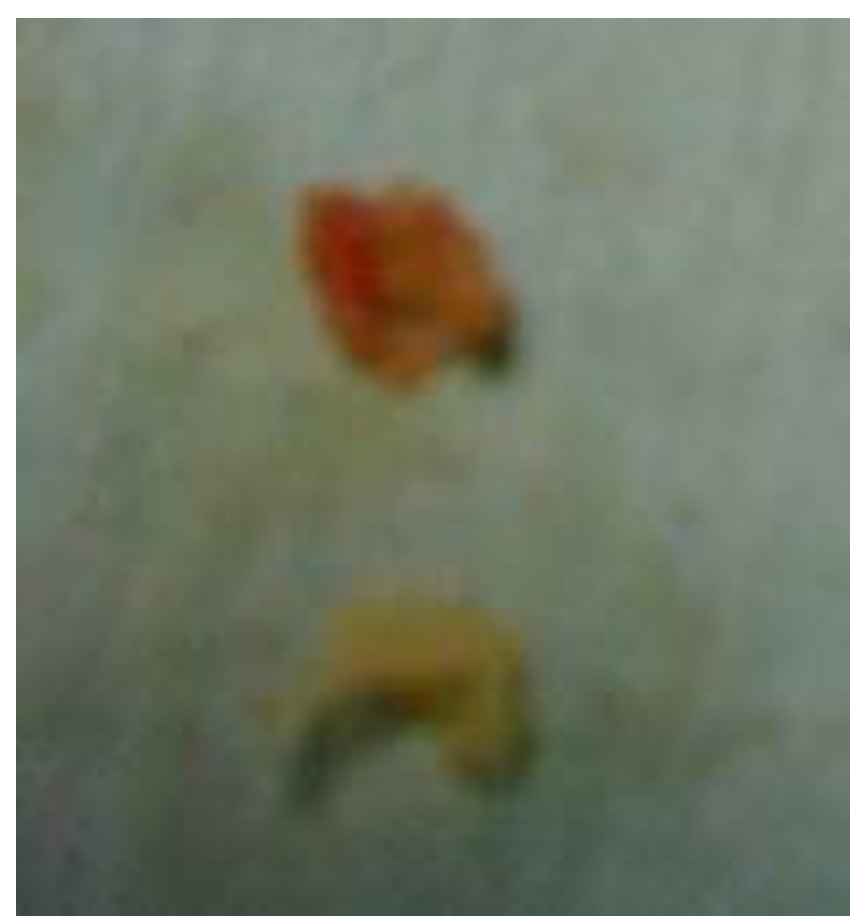

Figure 2

Pieces of bone wax curetted out from the bony craters. bleeding. It is nonabsorbable with no biochemical action. It achieves hemostasis by occluding the blood channels mechanically [1]. Once applied it essentially never goes away. Surgeon should be aware of the adverse effects of its use. It is known to interfere with bone healing and osteogenesis. It has been shown to reduce bacterial clearance in cancellous bone and to increase the risk of infection. In the presence of bone wax, the number of bacteria needed to produce osteomyelitis is reduced by a factor of $10^{4}$ $(10,000)[2]$.

Foreign-body granulomatous reaction due to bone wax has been reported in various surgical sites with different clinical implications, requiring surgical exploration in some cases. Bone wax granulomas have been reported in mastoid [3], sternototomy site, lumbar disc surgical site [4], at the cerebellopontine angle [5], in the subarachnoid space near medulla oblongata, in femoral neck osteoplasty site [1], in orbits, in cranial defects, after tibial tubercle elevation surgery and after foot surgery. In one instance, in which bone wax had been used to stop bleeding from the iliac crest after the harvesting of autogenous graft, the patient presented 19 years later with a large, symptomatic, retroperitoneal tumour associated with a foreign-body reaction, which had to be removed operatively [6].

\section{Conclusion}

Though inexpensive, easy to use with immediate effect on bleeding, bone wax should be used with caution after weighing the potential complications against the benefits. Bone wax is a foreign body and that there is always a possibility of foreign body granulomas following its use.

When necessary, bone wax should be used just for the time needed to achieve hemostasis. If it is left in place, care should be taken to avoid bone wax accumulation in the bony craters formed during surgery. Applying bone wax as a smooth layer by pasting with finger may lead to its lumpy formation in the bony craters and one should be careful about it.

\section{Consent}

Written informed consent was obtained from the patient for publication of this case report and any accompanying images. A copy of the written consent is available for review by the Editor-in-Chief of this journal.

\section{Competing interests}

The authors declare that they have no competing interests.

\section{Authors' contributions}

AQ searched the literature and helped in editing. AHK conceived the idea, searched the literature and wrote the paper. 


\section{References}

I. Lavigne M, Reddi Boddu Siva KR, Doyon J, Vendittoli P-A: Bone-wax granuloma after femoral neck osteoplasty. Can J Surg 2008, 5 I(3):E58-E60.

2. Nelson DR, Buxton TB, Luu QN, Rissing JP: The promotional effect of bone wax on experimental Staphylococcus aureus osteomyelitis. J Thorac Cardiovasc Surg 1990, 99:977-980.

3. Low WK, Sim CS: Bone Wax Foreign Body Granuloma in the Mastoid. ORL 2002, 64:38-40.

4. Eser Olcay, Cosar Murat, Aslan Adem, Sahin Onder: Bone wax as a cause of foreign body reaction after lumbar disc surgery: A case report. Advances in Therapy 2007, 24(3):.

5. Patel RB, Kwartler JA, Hodosh R: Bone wax as a cause of foreign body granuloma in cerebellopontine angle. J Neurosurg 2000, 92:362.

6. Verborgt O, Verellen K, Van Thielen F, Deroover M, Verbist L, Borms $\mathrm{T}$ : A retroperitoneal tumor as a late complication of the use of bone wax. Acta Orthop Belg 2000, 66:389-9l.

Publish with Bio Med Central and every scientist can read your work free of charge

"BioMed Central will be the most significant development for disseminating the results of biomedical research in our lifetime. "

Sir Paul Nurse, Cancer Research UK

Your research papers will be:

- available free of charge to the entire biomedical community

- peer reviewed and published immediately upon acceptance

- cited in PubMed and archived on PubMed Central

- yours - you keep the copyright 